\title{
Do marine gas hydrate deposits create heat flow anomalies on the seabed?
}

\section{Създават ли морските находища на газови хидрати аномалии на топлинния поток на морското дъно?}

\author{
Atanas Vasilev', Nikola Botoucharov ${ }^{2}$, Petar Petsinski ${ }^{1}$, Rositsa Pehlivanova ${ }^{1}$, Ivan Genov ${ }^{1}$, \\ Orlin Dimitrov', Dimitar Dimitrov ${ }^{1}$, Danail Yovchev ${ }^{2}$ \\ Атанас Василев ${ }^{1}$, Никола Ботушаров ${ }^{2}$, Петър Пецински ${ }^{1}$ Росица Пехливанова ${ }^{1}$, Иван Генов $^{1}$, \\ Орлин Димитров ${ }^{1}$, Димитьр Димитров", Данаил Йовчев ${ }^{2}$
}

\author{
${ }^{1}$ Институт по океанология - БАН, 9000 Варна; E-mail: gasberg@io-bas.bg \\ ${ }^{2}$ Софийски университет „Св. Климент Охридски“, 1504 София; E-mail: botnd@gea.uni-sofia.bg
}

\begin{abstract}
The aim of Stage 1 of the FNI project GEOHydrate is to prove the hypothesis that gas hydrates deposits (GHDs) create measurable temperature and heat flow (T\&HF) anomalies on the seafloor. We use a PetroMod ${ }^{\mathrm{TM}}$ model for 98 Ma basin analysis of the Western Black Sea basin, developed in GEOMAR, FRG. The model was run 2 times - with and without GH formation. The resultant difference of the heat flows on the seabed shows average heat flow anomaly above GHDs of $7 \mathrm{~mW} / \mathrm{m}^{2}$ and a maximum of $15 \mathrm{~mW} / \mathrm{m}^{2}$.
\end{abstract}

Keywords: gas hydrates, gas seeps, methane, basin analysis, Black Sea.

\section{Въведение}

Газовите хидрати (ГХ) са подобни на лед, но в кристалните им решетки от водни молекули е затворен газ. Те образуват находища на континенталния склон при дълбочина на водата над $500 \mathrm{~m}$ и дълбочина под морското дъно под $500 \mathrm{~m}$. При топене на ГХ остава вода и газ, който гори. От $1 \mathrm{~m}^{3}$ природен ГХ се отделят $\sim 150 \mathrm{~m}^{3}$ газ, предимно метан $\left(\mathrm{CH}_{4}\right)$.

Глобалните запаси от природен газ в ГХ надвишава количеството газ в традиционни находища десетократно. Програми за изследване и разработване на ГХ се изпълняват в Германия, Индия, Китай, Нова Зеландия, САЩ, Тайван, Южна Корея и Япония. Германия е изключение, защото в акваторията и отсъстват ГХ, но правителството финансира разработването на ГХ с 2 основни цели: развитие на иновативен научен потенциал и бъдещ износ на уникални технологии.

Тестове вече доказаха възможността за добив на газ от ГХ, но добиваният газ е на порядък поскъп от традиционния. Водещи в добивните технологии са Китай и Япония, които планират да започнат промишлен добив до 2027. Метанът в едно сондирано от Япония находище е $>1100 \mathrm{bcm}$ $\left(1 \mathrm{bcm}=10^{9} \mathrm{~m}^{3}\right)-$ количество, което покрива потреблението на Япония за 11 години.

В Европа най-обещаващите находища са открити в западната част на Черно море - в из- ключителните икономически зони на България и Румъния (БИИЗ и РИИЗ). Само находището в БИИЗ (фиг. 1a) може да направи България енергийно независима за повече от век (Vassilev, 2006).

Предварителни резултати показват, че над ГХ находище (ГХН) в БИИЗ съществуват съществени аномалии на температурата и топлинния поток (ТиТП; Vasilev, 2015). Моделът по сеизмичен профил, интерпретиран от Рореscu et al. (2006), определя ТиТП на дълбочина $5 \mathrm{~m}$ под дъното, защото in situ измервания в полигона с детайлни изследвания (фиг. 1a) показват, че температурите в седиментите на дълбочини $<2,5 \mathrm{~m}$ са нестационарни (Bialas et al., 2014). Мониторинг на ТиТП на 7 етапа от образуване на ГХН с програма Energy2D показва изменящи се аномалии на ТП до $\pm 25 \mathrm{~mW} / \mathrm{m}^{2}$ на фона на ТП на дъното, резултат от дълбочинен ТП от $32 \mathrm{~mW} / \mathrm{m}^{2}$ (Vasilev, 2015). Този опростен модел не отчита фактори със съществен ефект върху измеримите на морското дъно полета на ТиТП. Такива са скоростта на седиментация, релефа, контрастната топлопроводимост, миграцията на флуиди и др.

\section{Материали и методи}

За отчитане на ефектите от множеството фактори, които биха поставили под съмнение про- 

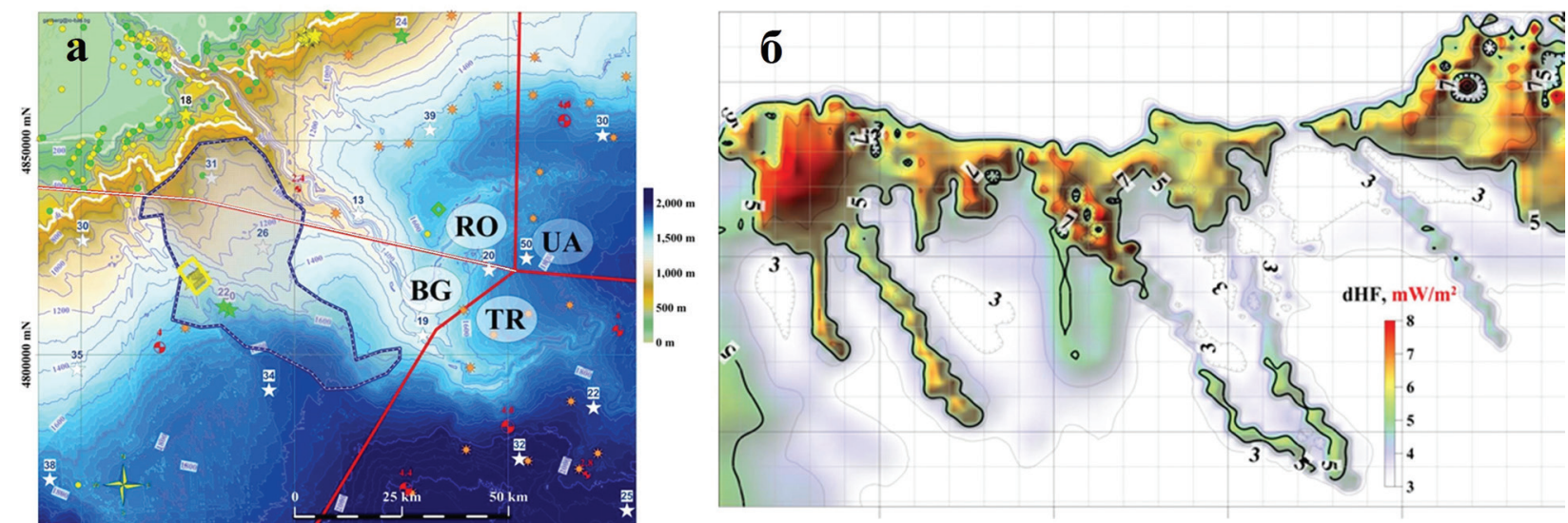

Фиг. 1. $a$ - батиметрична карта и ГХН в палеоделтата на Дунав уточнено по сеизмични и електромагнитни данни от експедиция MSM34-35, проект SUGAR, ФРГ (Bialas et al., 2014): задимен полигон със син контур - площ, в която са регистрирани BSR/ГX; бяла изобата $650 \mathrm{~m}$ - латерална граница на зона на стабилност на метанови хидрати; червени линии - граници на изключителните икономически зони в Черно море (границата между България и Румъния все още не е утвърдена); жълт правоъгълник - полигон с детайлни 3D сеизмични и CSEM изследвания, измерване на топлинен поток и геолого-геохимичен пробоотбор; петольчни звездички - станции с измерване на $\mathrm{T \Pi}, \mathrm{mW} / \mathrm{m}^{2}$; кафяви осмолъчни звездички - потенциални кални вулкани, установени по проби с кална брекча; червени полузапълнени крьгчета епицентри на земетресения; $\sigma$ - моделни аномалии на ТП, $\mathrm{mW} / \mathrm{m}^{2}$ над ГХН; съвременно състояние след 98 Ма еволюция на басейна. Аномалията в лявата част на фиг. 16 , очертана по изолиния $7 \mathrm{~mW} / \mathrm{m}^{2}$, е разположена приблизително над северната половина на площта с BSR/ГX на фиг. 1а.

верката на основната работна хипотеза на Етап 1 на проект ГЕОХидрат беше решено моделното изследване да бъде извършено с програмния пакет за басейнов анализ PetroMod" Schlumberger CCL. Програмата е лидер в моделиране еволюцията на басейни, образуването и миграцията на въглеводороди и формирането на находища на нефт, газ и ГХ. Детайлно описание на модела е публикувано от Burwicz, Haeckel (2019). Литостратиграфските параметри на модела на Черно море се основават на съвременните сеизмични интерпретации на Nikishin et al. $(2015 \mathrm{a}, \mathrm{b})$. Моделният куб включва район от дълбоководната палеоделта на Дунав в БИИЗ и РИИЗ с размери $\mathrm{X} \times \mathrm{Y} \times \mathrm{Z} 250 \times 160 \times 18 \mathrm{~km}$. Той се състои от 40 седиментни слоя, представящи геоложката история от най-ранната пост-рифт фаза преди 98 Ма до днес с 103 хоризонта, регистрирани на дълбочинни сеизмични профили с развивка 18 s (Nikishin et al., 2015b). Разделителните способности на модела по X и Y ca съответно $\sim 3,1$ и $\sim 2,7 \mathrm{~km}$. Моделът се изпълнява на съвременна работна станция за 6 часа, а резултатите са грид-данни, от които могат да се построят над 20000 карти.

За изследване на аномалиите на ТП, предизвикани от образуването на ГХН, са получени резултати за полето на ТП в приповърхностните седименти от 2 симулационни модела - с и без образуване на ГХ. Търсените аномалии на ТП са в разликата на резултантните полета на ТП.

\section{Резултати}

Резултатьт от PetroMod ${ }^{\mathrm{TM}}$ модела показва средни аномалии от $\sim 7 \mathrm{~mW} / \mathrm{m}^{2}$ с максимум от $15 \mathrm{~mW} / \mathrm{m}^{2}$ над ГХН (фиг. 1б). Формата на изолиниите на аномалния ТП е сходна както с тази на изолиниите на масите на ГХ на дълбочини $100 \mathrm{~m}$, така и на основните маси на $\sim 400 \mathrm{~m}$.

\section{Дискусия}

Основни недостатьци на представения модел са:

- С изключение на данните за релефа на дъното, параметрите на модела са оценъчни, а не резултат от измерване. Този недостатък няма да бъде преодолян скоро, защото изисква дълбоководно сондиране;

- Модельт работи единствено с метанови хидрати, но високата нефтоперспективност на района предполага ГХ със състав на газа, включващ метан, неговите пьрви хомолози и $\mathrm{CO}_{2}$. В това отношение получените аномалии на ТП са занижени, защото допълнителното образуване на ГХ е сьпроводено с допълнително отделяне на топлина;

- Модельт е без разломи и това занижава повърхностния топлинния поток. Отсъствието на разломи препятства вертикалната миграция, което води до генериране на по-малка маса ГХ и отделяне на по-малко топлина от екзотермичния процес на хидратообразуване;

- Началните и гранични условия на изменение на климата, морското ниво, солеността и 
ТП са известни схематично. Приложеният консервативен подход при подбора им е подходящ за ресурсни оценки, но не толкова за проверка на хипотези. Например измененията на климата и морското ниво в Черно море след последния ледников максимум са довели до значително топене на ГХ в периферната част на ЗСГХ. Така аномалиите на ТП от екзотермичния процес на образуване на ГХ ще бъдат намалени от ендотермичния процес на дисоциация на ГХ.

\section{Заключение}

Хипотеза на Етап 1 на проект ГЕОХидрат е доказана моделно - над ГХН се набюдават измерими нестационарни аномалии на ТП. От изброените недостатьци на модела единствено последният намалява топлинния ефект от образуването на ГХН, но той „работи“ само в перифирията на ЗСГХ, тъй като морското ниво е било по-ниско от сьвременното с 100-150 m.

Възможността ГХН да бъдат изследвани с геотермични методи ускорява процеса на тяхното разработване и мониторинг. Геотермията е единствен геофизичен метод с параметър геоложко време в своите уравнения, което позволява изследване на процеси и тяхното датиране. Тези идеи и тяхната количествена оценка подсказват основната хипотеза на Етап 2 на проекта, че от аномалиите на ТиТП над ГХН може да бъде възстановен 4D процесът на тяхното образуване. Подобни резултати ще направят промишления добив на метан от ГХ реалност.

За разлика от шистовия газ и други ресурси, ГХ могат да бъдат експлоатирани без да засягат околната среда. Чистият природен газ от ГХ може да играе важна роля в бъдещата европейска енергийна система. Той би могъл: а) да повиши сигурността на енергийните доставки; б) да допринесе за намаление на емисиите на $\mathrm{CO}_{2}$, заменяйки въглищата; в) да допълва източниците на възобновяема енергия, като доставя електричество в периодите на безветрие и помалко светлина. ГХ биха могли да заменят европейския конвенционален газ, който ще се изчер- пи през следващите десетилетия, и значително да смекчат нарастващата зависимост на Европа от внос на природен газ. Разработването на технология за добив на метан посредством заместването му в хидрата от $\mathrm{CO}_{2}$ ще направи добивания метан единствен енергиен източник не само без, но и с отрицателен въглероден отпечатьк върху атмосферата. Така разработването на ГХ технологии е принос към подобряване на екологичното състояние и климата на планетата.

Благодарности: Изследването е финансирано от Фонд „Научни изследвания““ по от проект КП-06-ОПР 04/7 от 18.12.2018 ГЕОХидрат „Геотермична еволюция на морски находища на газови хидрати - палеоделтата на Дунав, Черно море“. Авторите благодарят на Dr Ewa Burwicz, GEOMAR, без чиято помощ получаването на тези резултати беше невъзможно.

\section{Литература \\ References}

Bialas, J., I. Klaucke, M. Haeckel. 2014. Report No 15, MSM Cruise 34, Leg 1\&2, SUGAR site, 111 p.

Burwicz, E., M. Haeckel. 2019. Basin-scale estimates on the petroleum components generation in the Western Black Sea basin based on the 3-D numerical model. - Mar. Pet. Geol., $113,104-122$.

Nikishin, A. M., A. Okay, O. Tüysüz, A. Demirer, N. Amelin, E. Petrov. 2015a. The Black Sea basins structure and history: new model based on new deep penetration regional seismic data. Part 1: Basins structure and fill. - Mar. Pet. Geol., 59, 638-655.

Nikishin, A. M., A. Okay, O. Tüysüz, A. Demirer, M. Wannier, N. Amelin, E. Petrov. 2015b. The Black Sea basins structure and history: new model based on new deep penetration regional seismic data. Part 2: Tectonic history and paleogeography. - Mar. Pet. Geol., 59, 656-670.

Popescu, I., M. De Batist, G. Lericolais, H. Nouzé, J. Poort, N. Panin, W. Versteeg, H. Gillet. 2006. Multiple bottomsimulating reflections in the Black Sea: potential proxies of past climate conditions. - Mar. Geol., 227, 163-176.

Vassilev, A., 2006. Optimistic and pessimistic model assessments of the Black Sea gas hydrates. - C. R. Acad. Bulg. Sci., 59, 5, 543-550.

Vasilev, A., 2015. Geothermal evolution of gas hydrate deposits: BEEZ in the Black Sea. - C. R. Acad. Bulg. Sci., 68, 9, $1135-1144$. 